\title{
Tempforming as an Advanced Processing Method for Carbon Steels
}

\author{
Anastasiya Dolzhenko, Rustam Kaibyshev and Andrey Belyakov * \\ Laboratory of Mechanical Properties of Nanostructured Materials and Superalloys, Belgorod State University, \\ 308015 Belgorod, Russia; dolzhenko_a@bsu.edu.ru (A.D.); rustam_kaibyshev@Bsu.edu.ru (R.K.) \\ * Correspondence: belyakov@bsu.edu.ru; Tel.: +7-4722-585457
}

Received: 28 October 2020; Accepted: 20 November 2020; Published: 24 November 2020

\begin{abstract}
The microstructural mechanisms providing delamination toughness in high-strength low-alloyed steels are briefly reviewed. Thermo-mechanical processing methods improving both the strength and impact toughness are described, with a close relation to the microstructures and textures developed. The effect of processing conditions on the microstructure evolution in steels with different carbon content is discussed. Particular attention is paid to tempforming treatment, which has been recently introduced as a promising processing method for high-strength low-alloyed steel semi-products with beneficial combination of strength and impact toughness. Tempforming consists of large strain warm rolling following tempering. In contrast to ausforming, the steels subjected to tempforming may exhibit an unusual increase in the impact toughness with a decrease in test temperature below room temperature. This phenomenon is attributed to the notch blunting owing to easy splitting (delamination) crosswise to the principle crack propagation. The relationships between the crack propagation mode, the delamination fracture, and the load-displacement curve are presented and discussed. Further perspectives of tempforming applications and promising research directions are outlined.
\end{abstract}

Keywords: high-strength carbon steels; thermo-mechanical treatment; ausforming; tempforming; strength; impact toughness; ductile-brittle transition temperature

\section{Introduction}

Carbon steels are widely used structural materials. One of drawbacks of such steels is their relatively high temperature of ductile-brittle transition in the hardened state that makes the steels brittle at temperatures just below room temperature and, correspondingly, restricts their applications at lowered temperatures. Comprehensive studies of the fracture mechanisms and the conditions of the ductile-brittle transition have been carried out from the middle of the last century. According to the Yoffee diagram, an increase in the resistance to brittle fracture and/or a decrease in the effective yield stress should decrease the ductile-brittle transition temperature [1]. A common approach to suppress the brittle intercrystalline fracture involves the grain refinement and grain boundary precipitations. On the other hand, a decrease in the effective flow stress at the crack tip can be achieved in the microstructure, which spontaneously delaminates ahead of the crack crosswise to the crack propagation direction and, thus, blunts the crack tip.

Both approaches, i.e., the grain refinement and the delamination, have been utilized through thermo-mechanical treatment that is commonly known as ausforming, under the conditions of stable or meta-stable austenite. The hot working of austenite is intended to refine the deformation microstructure along with a certain work hardening [2]. The latter changes the intergranular fracture mode along prior austenite grain boundaries to a transgranular fracture across prior austenite grains. Moreover, the hot rolling of austenite results in heterogeneous banding of the original cast structure, which leads to crack 
blunting and increases the impact strength, owing to delamination along the segregation/inclusion bands. The fracture mechanisms and ausforming treatments improving the impact toughness are briefly reviewed and discussed in Sections 2 and 3.

An alternative approach to increase the toughness and decrease the ductile-brittle transition temperature of plain carbon steels has been suggested by Kimura et al. [3]. The proposed method consists in the formation of a submicrocrystalline lamella type microstructure with a uniform dispersion of secondary phase particles by means of warm rolling under conditions of tempering. Such thermo-mechanical treatment, which has been referred to as tempforming, provides an outstanding combination of mechanical properties in low-alloyed carbon steels. Processed steel has high strength due to the reduction of grain size and precipitation hardening as well as high impact toughness owing to delamination toughness. A superior combination of the ultimate tensile strength of $1800 \mathrm{MPa}$ and impact toughness (KCV) of almost $240 \mathrm{~J} / \mathrm{cm}^{2}$ at room temperature has been obtained in a medium carbon low-alloyed steel [3]. The present review is aimed to highlight the various benefits of tempforming in a brief comparison with ordinary thermo-mechanical treatments used to improve impact toughness of high-strength steels and outline the most promising directions for further research. The developed microstructures and fracture behavior of low-alloyed steel subjected to tempforming are considered in Section 4. The effects of alloying extent and tempforming conditions on the strength and impact toughness of low-alloyed steels are critically reviewed and discussed with a reference to underlying structural mechanisms responsible to deformation behavior and fracture. Specific emphasis is placed on the fracture mechanisms that may unexpectedly lead to increasing the impact toughness in carbon steels while decreasing the test temperature. Finally, prospective investigations and applications of tempforming and related phenomena are summarized in Section 5.

\section{Impact Toughness}

\subsection{Fracture Mechanisms}

Generally, structural steels and alloys may exhibit two types of fracture behavior during impact tests, either ductile or brittle [3-5]. The dominant fracture mechanism is governed by microstructure and testing conditions. The ductile fracture is characterized by general yield when remarkable plastic deformation precedes the failure. The specimen fracture in such a case is associated with a gradual change in the cross section. The ductile fracture of impact specimen is accompanied by stable crack propagation when the crack motion follows local plastic deformation and is controlled by applied load. The ductile crack growth occurs with relatively large energy consumption, which results in high impact toughness. The most frequently referred to mechanism of ductile fracture consists in steady void nucleation followed by their growth and coalescence, finally leading to specimen failure. The corresponding fracture surface is composed with many dimples with tearing edges (Figure 1a) [6]. The void nucleation is commonly attributed to dislocation storage caused by some obstacles for dislocation motion and microstrain incompatibilities [5,7-9]. Various non-metallic inclusions and second phase particles were frequently considered as void nucleation centers [10].

In contrast to ductile fracture, brittle fracture is associated with unstable crack propagation, which starts under applied stress below the general yield stress [3,4]. Generally, the brittle fracture takes place when the effective yield stress exceeds the critical stress for material detachment (or cleavage) at the crack tip. Therefore, the brittle fracture occurs without notable plastic deformation at the front of the growing crack. In this case, the crack grows spontaneously and does not consume remarkable energy, resulting in pretty low impact toughness. The microstructural mechanisms of brittle fracture of structural steels and alloys consist in intercrystalline splitting and/or plane cleavage of crystal lattice. The latter is characterized by wavy steps on the fracture surface (Figure 1b) [6]. A plane of $\{100\}$ is a typical cleavage plane in ferrite/martensite [4]. 


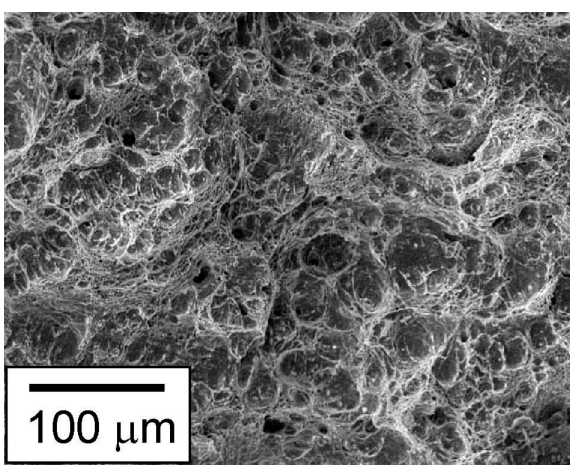

(a)

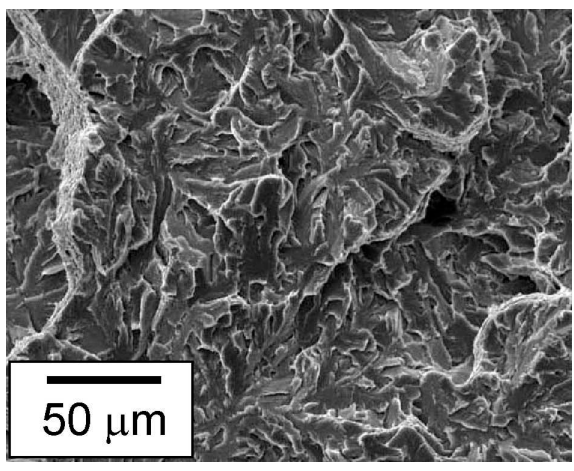

(b)

Figure 1. Examples of ductile (a) and brittle (b) fracture surfaces of $10 \mathrm{Cr} 9 \mathrm{WMoVNbB}$ steel samples subjected to impact tests at $20^{\circ} \mathrm{C}$ and $-80^{\circ} \mathrm{C}$, respectively. Reproduced with permission from [6], Springer Nature, 2016.

\subsection{Ductile-Brittle Transition}

The impact toughness of plain carbon and high-strength low-alloyed steels depends substantially on temperature of impact tests (Figure 2a) [1]. Typically, the steel impact toughness slightly decreases with a decrease in the test temperature to or below room temperature followed by drastic drop as the temperature further approaches cryogenic range. Therefore, the temperature dependence of impact toughness is characterized by two shelves, i.e., the lower shelf in the region of low temperature and upper shelf in the domain of around room temperature and upward. The inflection corresponds to ductile-brittle transition temperature. The change in the impact toughness with the test temperature is associated with the change in fracture mechanism. Namely, commonly ductile fracture at relatively high temperatures becomes brittle as temperature decreases. The transition from ductile to brittle fracture occurs in rather wide temperature interval, where the percentage of brittle fracture gradually increases to $100 \%$ at expense of ductile fracture [4].

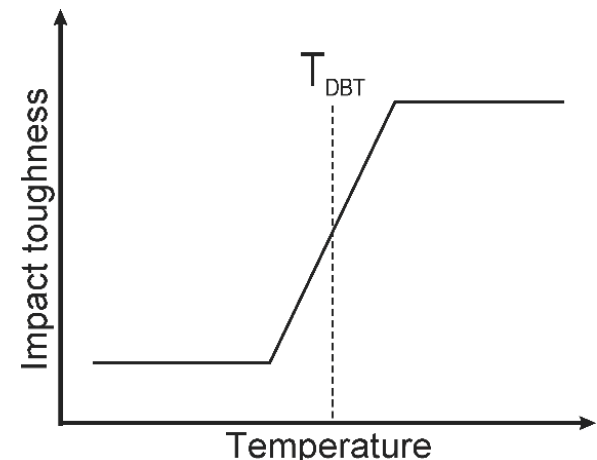

(a)

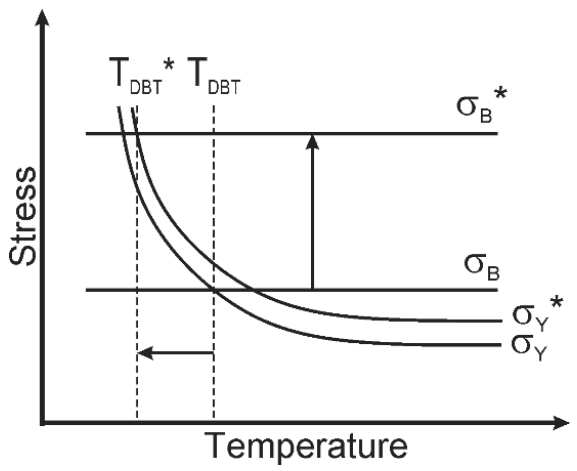

(b)

Figure 2. Schematic relationship between impact toughness and temperature of ductile-brittle transition, $\mathrm{T}_{\mathrm{DBT}}(\mathbf{a})$ and effects of brittle fracture stress, $\sigma_{\mathrm{B}}$, and effective yield stress, $\sigma_{\mathrm{Y}}$, on $\mathrm{T}_{\mathrm{DBT}}(\mathbf{b})$. Reproduced with permission from [1], AAAS, 2008.

The change in the fracture mechanisms and the impact toughness can be illustrated by the Yoffee diagram, which compares the temperature effects on brittle fracture stress and effective yield stress (Figure 2b) [1]. The former is almost temperature independent, while the latter rapidly increases with a decrease in temperature. Upon mechanical loading, the growing stress at the crack tip can reach either general yield stress $\left(\sigma_{\mathrm{Y}}\right)$ leading to plastic deformation and subsequent ductile crack propagation or brittle fracture stress $\left(\sigma_{\mathrm{B}}\right)$, when fracture occurs in brittle manner. Since the fracture mode is controlled by the lower stress among the brittle fracture and yield stresses, brittle fracture occurs at 
low temperatures while ductile fracture is more probable at higher temperatures; the intersection point of the effective yield stress and the brittle fracture stress can be considered as ductile-brittle transition temperature. According to the Yoffee diagram, the temperature range of ductile fracture can be expanded toward low temperatures due to the increase in brittle fracture stress. This can be realized owing to grain refinement. In fact, the grain refinement increases both the brittle fracture stress and the effective yield stress. However, an increment in the brittle fracture stress with a decrease in the grain size exceeds the corresponding increase in the effective yield stress [11]. This beneficial effect of grain size on mechanical properties has been encouraging the development of processing methods involving the grain refinement.

\section{Thermo-Mechanical Treatment}

\subsection{Ausforming}

Starting from the middle of the last century, the great attention has been paying to thermal and thermo-mechanical treatments in combination with the modification of the chemical composition of high-strength low-alloyed steels in order to obtain a specific microstructure, which should provide a high level of strength and toughness. It has been observed that surprisingly high strength could be obtained in low-alloy (mainly nickel-chromium) steels by warm working of austenite prior to martensite (or bainite) transformation [12-14]. Such thermo-mechanical treatment involving the deformation of meta-stable austenite has been called ausforming [15]. Ausforming consists of plastic deformation in the temperature range between $\mathrm{Ar}_{1}$ and $\mathrm{M}_{\mathrm{S}}$ followed by quenching to martensite before bainite/pearlite transformation (Figure 3a). Then, the martensite in ausformed steels is subjected to conventional tempering treatment. Some early examples of the improvement of mechanical properties owing to ausforming are listed in Table 1 [12-14,16].

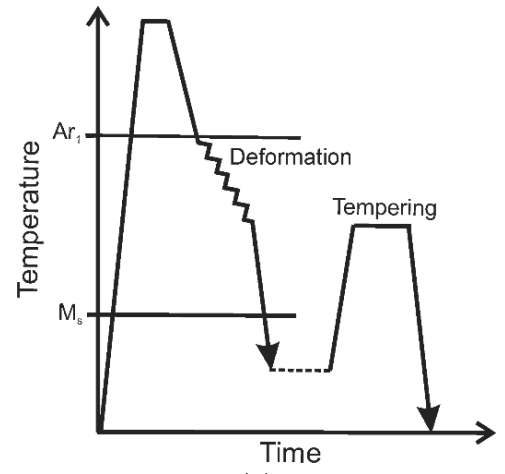

(a)

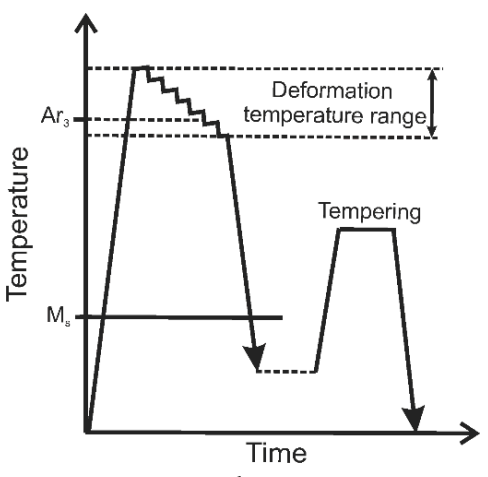

(b)

Figure 3. Schematics of ausforming (a) and modified ausforming (b) treatments.

Table 1. Offset yield strength $\left(\sigma_{0.2}\right)$, ultimate tensile strength (UTS), elongation $(\delta)$, and impact toughness $(\mathrm{KCV})$ in some steels subjected to ausforming or conventional quenching-tempering treatment.

\begin{tabular}{ccccccc}
\hline Steel & $\mathbf{T},{ }^{\circ} \mathbf{C}$ & $\sigma_{\mathbf{0 . 2}}{ }^{*}, \mathbf{M P a}$ & $\mathbf{U T S}{ }^{*}, \mathbf{M P a}$ & $\delta^{*}, \boldsymbol{\%}$ & $\mathbf{K C V}^{*}, \mathbf{J} \cdot \mathbf{c m}^{-\mathbf{2}}$ & Ref. \\
\hline $0.35 \% \mathrm{C}$ & 20 & $2050 / 1690$ & $2260 / 2030$ & $7.5 / 8.5$ & - & {$[12]$} \\
$0.40 \% \mathrm{C}$ & 20 & $2190 / 1790$ & $2370 / 2160$ & $6.5 / 8.1$ & - & {$[12]$} \\
$0.49 \% \mathrm{C}$ & 20 & $2120 / 1830$ & $2300 / 2080$ & $5.5 / 7.6$ & - & {$[12]$} \\
4340 & 20 & $2050 / 1820$ & $2280 / 2100$ & $8 / 10$ & $14.7 / 7.8$ & {$[13]$} \\
4340 & -80 & - & - & - & $11.8 / 4.9$ & {$[13]$} \\
30CrNiMo & 20 & $1800 / 1500$ & $2100 / 1800$ & $6 / / 10$ & - & {$[16]$} \\
$40 \mathrm{Cr} 3 \mathrm{Mo} 3 \mathrm{SiV}$ & 20 & $2100 / 1800$ & $2370 / 2160$ & $4 / 5$ & - & {$[14]$} \\
40CrNi2Mo & 20 & $1970 / 1650$ & $2180 / 1930$ & $10 / 10$ & - & {$[14]$} \\
\hline
\end{tabular}

It has been suggested that the structural mechanisms responsible for superior strength owing to ausforming are associated with direct inheritance by the martensite of defects generated during 
the warm working of the austenite [14,17]. Recently, the dislocation density that inherited from the deformed austenite has been confirmed as the main strengthener, irrespective of grain refinement caused by plastic deformation of austenite [18]. The most important inherited structural/substructural elements are dislocation tangles, sub-boundaries, and finely dispersed carbide particles. The ausforming is, therefore, controlled by two principal processes; namely, plastic deformation of meta-stable austenite and subsequent martensitic transformation.

The plastic deformation for ausforming can be carried out by various methods like rolling and forging for large scale production. The most important deformation parameters for a certain processing method are the deformation temperature and total strain [14]. The different effect of the warm working strain on the subsequent martensitic transformation has been reported depending on the transformation mechanisms [19]. The plate martensite formation is scarcely affected by previous warm working, whereas austenite tends to be mechanically stabilized at a pre-strain level above $20 \%$ against the lath martensite formation. This different strain effect during ausforming on martensitic transformation has been attributed to different effect of austenite dislocation substructure on the growth of martensite plate and laths. On the other hand, the strength of lath martensite depends significantly on the deformation of austenite in the range of small strains, where the dislocation density is greatly affected by the strain. $\mathrm{M}_{\mathrm{S}}$ temperature increases with an increase in pre-strain to a critical value, and then decreases approaching a constant level with further pre-straining [20].

An increase in ausforming temperature increases the probability of detrimental phase transformations like formation of coarse granular and/or plate-like bainite during warm working of austenite that increases the size of final structural elements and reduced the strengthening [21]. In contrast, decreasing the ausforming temperature enhances the effectiveness of warm working to create the highly dislocated substructure in austenite. Moreover, a decrease in the ausforming temperature promotes the refinement of microstructure that is desirable for impact toughness [22]. The temperature and strain of warm deformation of austenite should be optimized in order to minimize the prior austenite grain size with sufficiently high dislocation density on the one hand, and reduce the working load as much as possible on the other.

Similar to conventional heat treated structural steels, carbon is the essential alloying element governing the mechanical properties of ausformed steels [14]. Generally, an increase in the carbon content increases the strengthening of ausformed steels, although effectiveness of strengthening by carbon decreases as its content increases. Other alloying elements may also enhance the ausforming effect $[14,23]$. Such elements as chromium and molybdenum are very beneficial for steels intended for ausforming. These elements separate the ranges of pearlite and bainite transformations and, therefore, expand the range of meta-stable austenite, making easier the selection of appropriate processing conditions. On the other hand, the carbide forming elements result in finely dispersed particles that precipitate in austenite during warm working, increasing the strength of ausformed steels.

\subsection{Modified Ausforming}

In spite of a great success in using the ausforming for improvement of mechanical properties of structural steels, its applicability has some limitations. The most serious drawback of ausforming is a requirement of certain stability of undercooled austenite for hardenable steels. An increased demand for high-strength low-alloyed steels with greatly improved impact toughness at lowered temperatures has encouraged extensive research works dealing with relevant thermo-mechanical treatments. An original solution to the problem has been found. This consists in hot rolling of the steels in the temperature range of stable austenite followed by quenching to martensite and tempering (Figure 3b). Such processing technique has been referred to as modified ausforming, to distinguish it from ordinary ausforming, which involves warm working of metastable austenite [24,25]. The modified ausforming is also known as high temperature thermo-mechanical treatment [14,23]. Of particular interest is an application of modified ausforming to increase the low temperature impact properties 
of low- and medium-alloyed steels, whose S-curve locates in the range of short times [25]. Arbitrary selected examples of steel properties after modified ausforming are shown in Table 2 [23,26-30].

Table 2. Offset yield strength $\left(\sigma_{0.2}\right)$, ultimate tensile strength (UTS), elongation $(\delta)$, and impact toughness $(\mathrm{KCV})$ of some steels subjected to modified ausforming or conventional quenching-tempering treatment.

\begin{tabular}{ccccccc}
\hline Steel & $\mathbf{T}^{\circ}{ }^{\circ} \mathbf{C}$ & $\sigma_{0.2}{ }^{*}, \mathbf{M P a}$ & $\mathbf{U T S}^{*}, \mathbf{M P a}$ & $\delta^{*}, \%$ & $\mathbf{K C V}^{*}, \mathbf{J} \cdot \mathbf{c m}^{-2}$ & Ref. \\
\hline 50CrNi4Mo & 20 & $1850 / 1650$ & $2110 / 1870$ & $25 / 29$ & - & {$[26]$} \\
$40 \mathrm{CrNiMo}$ & 20 & - & $2460 / 2280$ & $9.8 / 9.7$ & - & {$[27]$} \\
$0.5 \% \mathrm{C}, 2.6 \% \mathrm{Si}$ & 20 & $2130 / 1930$ & $2460 / 2250$ & $5 / 5$ & - & {$[28]$} \\
$0.6 \% \mathrm{C}, 1.6 \% \mathrm{Si}$ & 20 & $2080 / 1820$ & $2550 / 2160$ & $7 / 5.5$ & - & {$[28]$} \\
$0.6 \% \mathrm{C}, 2.2 \% \mathrm{Si}$ & 20 & $2320 / 1900$ & $2700 / 2200$ & $7 / 6$ & - & {$[28]$} \\
$0.6 \% \mathrm{C}, 2.6 \% \mathrm{Si}$ & 20 & $2230 / 1930$ & $2700 / 2250$ & $7 / 5$ & - & {$[28]$} \\
20CrMnB & 20 & - & $1630 / 1570$ & $39.5 / 30$ & - & {$[29]$} \\
$0.4 \mathrm{C}-\mathrm{Ni}-\mathrm{Cr}-\mathrm{Mo}$ & 20 & $1680 / 1500$ & $1940 / 1800$ & $15 / 10$ & $15 / 10$ & {$[30]$} \\
$0.4 \mathrm{C}-\mathrm{Ni}-\mathrm{Cr}-\mathrm{Mo}$ & -80 & - & - & - & $13 / 6$ & {$[30]$} \\
4340 & 20 & $1720 / 1460$ & $2200 / 1850$ & $9.8 / 5.8$ & $13.5 / 10.8$ & {$[23]$} \\
4340 & -80 & - & - & - & $12.6 / 5$ & {$[23]$} \\
\hline
\end{tabular}

* Numerator corresponds to modified ausforming, denominator - conventional quenching-tempering treatment.

Early studies on modified ausforming have revealed two factors affecting the impact strength [24]. Both of them are associated with the change in the fracture mode. First is the change from intergranular fracture along prior austenite grain boundaries to transgranular fracture. The former frequently occurs if the austenite experienced recrystallization during hot deformation treatment, whereas the latter happens in the steels with non-recrystallized (work hardened) austenite. The second is associated with the mechanism of transgranular fracture, which should proceed as delamination. This fracture mechanism is closely connected with segregations leading to sulfides with brittle interfaces. The steels subjected to modified ausforming are characterized by planar arrangement of sulfide inclusions that delamination along the rolling plane, resulting in crack blunting and high impact toughness in longitudinal specimens [24,31].

The beneficial effect of modified ausforming on the mechanical behavior of high-strength steels consists in simultaneous enhancement of both impact toughness and strength. An increase in rolling reduction during modified ausforming leads to direct increase in the strength while ductility does not reduce. Moreover, the steels subjected to modified ausforming exhibit lower ductile-brittle transition temperature as compared to those processed by conventional quenching and tempering [32]. The desirable microstructural state that may provide this useful effect is associated with cell substructure with high dislocation density that evolves in austenite and then is inherited by martensite [25]. The cell substructure consisting of movable dislocations that is introduced to martensite through the transformation has been suggested as being responsible for relieving the high stress concentration at a crack tip, improving ductility. In addition, the dislocation cell substructure enhances the dispersion of second-phase particles in martensite that is favorable for strength and ductility [33]. It should be noted here retained austenite itself does not contribute to the excellent mechanical properties of the steels subjected to modified ausforming, because these steels are commonly characterized by a rather small amount of retained austenite [25].

The cooling regime following the modified ausforming is another important factor affecting the final microstructure and properties of the steels. In order to maintain the beneficial ausforming effect, cooling of the processed steels should be carried out as fast as possible to prevent any static recrystallization and grain growth processes that can remove the developed dislocation substructures [25]. On the other hand dynamic recrystallization during hot working under conditions of modified ausforming may lead to useful microstructure consisting of fine grains with irregular boundaries and dislocation cell substructure [34-37]. Dynamic recrystallization rapidly develops in austenite with a rather low stacking fault energy during hot deformation. The new grains are formed due to local migration of grain boundaries (bulging) towards the high dislocation density [35]. Such a mechanism of dynamic recrystallization is classified as discontinuous [38]. The dynamic grain size decreases with 
decreasing temperature and/or increasing strain rate (Figure 4) [39-45]. Note in Figure 4 that the strong temperature/strain rate dependence of dynamic grain size under conditions of hot working becomes weaker with a decrease in deformation temperature because of the change in dynamic recrystallization mechanism. Thus, the required structural state with a grain size of less than a micrometer can be obtained by processing at relatively low temperatures.

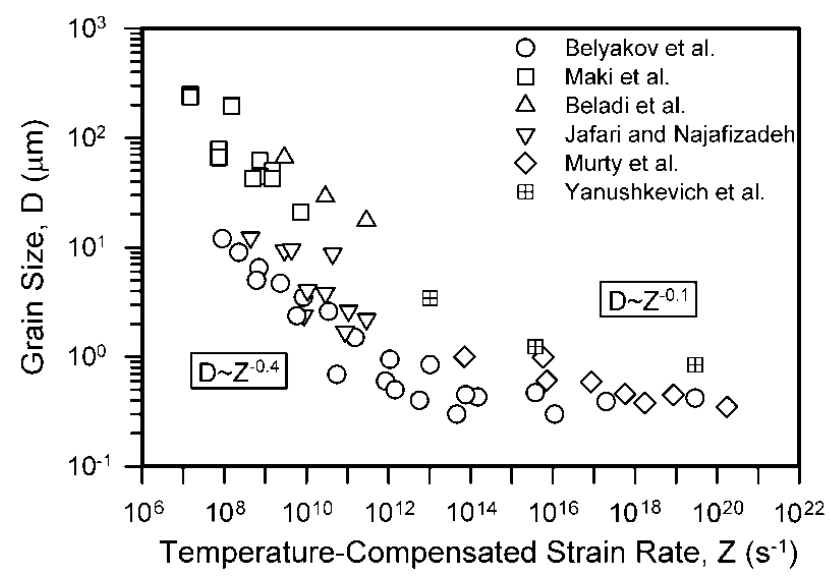

Figure 4. Effect of temperature-compensated strain rate on the grain size evolved by dynamic recrystallization. Reproduced with permission from from [45], Elsevier, 2016.

Ability of grain boundaries to migrate decreases with decreasing deformation temperature that slows down the kinetics of discontinuous dynamic recrystallization (Figure 5) [46]. Under conditions of warm working at relatively low temperatures, the austenite microstructure evolution is accompanied by the development of so-called continuous dynamic recrystallization resulting from an increase in the misorientation of deformation sub-boundaries to typical values of ordinary grain boundaries and the formation of a continuous net of strain-induced grain boundaries [38]. Continuous dynamic recrystallization is characterized by low kinetics, so the formation of a homogeneous ultrafine-grained microstructure during warm working requires large strains $[38,46]$. A promising way to obtain ultrafine grained austenite is the treatment under intermediate temperature conditions between discontinuous and continuous dynamic recrystallization, when the two mechanisms accelerate each other (Figure 5). Onset of discontinuous dynamic recrystallization in the transition region follows the high density of strain-induced high-angle grain boundaries.

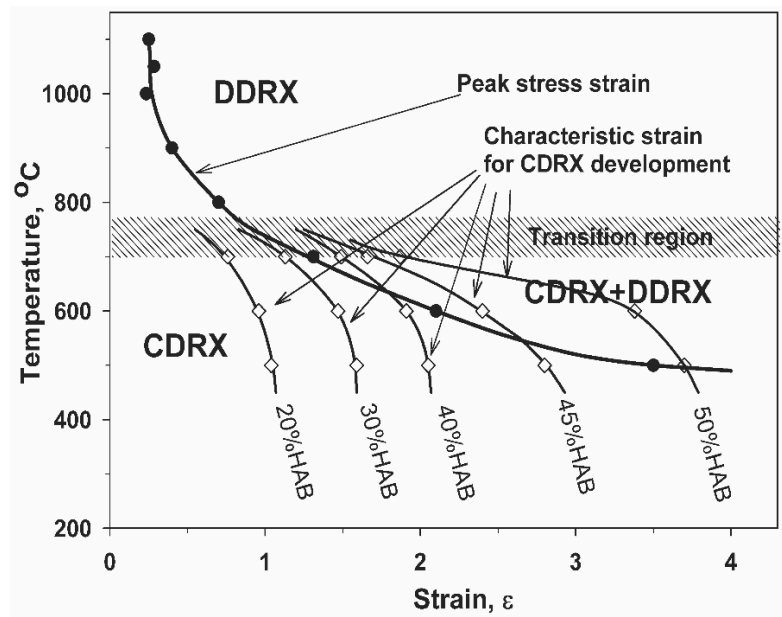

Figure 5. Effect of deformation conditions on the initiation of discontinuous dynamic recrystallization (DDRX) corresponding roughly to peak stress strain or on the development of continuous dynamic recrystallization (CDRX) indicated by various percentage of high-angle grain boundaries (HAB). Reproduced with permission from from [46], Elsevier, 2013. 
The thermo-mechanical treatment involving hot working under conditions of discontinuous dynamic recrystallization followed by gradual decrease in temperature down to two-phase (austenite-ferrite) domain of low-alloyed steels has been referred to as controlled rolling [47]. An advantage of this technique is the beneficial microstructure evolved in two stages, i.e., the austenite grain refinement owing to discontinuous dynamic recrystallization followed by work hardening assisted by partial $\gamma-\alpha$ phase transformation. An increase in strain in the two phase domain improves both the strength and impact toughness along with a decrease in ductile-brittle transition temperature. The highly elongated grains/sub-grains with dislocation cell substructure evolved during controlled rolling have been considered as the main factors responsible for the improved mechanical properties $[23,30,47]$. An embrittlement across the rolled plate thickness caused by crystallographic texture and plan sulphide distribution is responsible to delamination and notch blunting upon impact tests, while the high dislocation density strengthens the steels.

In order to obviate the harmful effect of static recrystallization and grain growth on the properties of steels subjected to modified ausforming, the steels are alloyed with some carbide forming elements, typically niobium. The effect of solute drag and dispersed precipitations on the recrystallization kinetics in plain-carbon $(\mathrm{C})$ and $\mathrm{Nb}$-modified $(\mathrm{Nb})$ steels is schematically shown in Figure 6 [48]. Both the recrystallization start (Rs) and finish (Rf) are significantly delayed in Nb-modified steel. It is important to note that $\mathrm{Nb}$ solute plays a crucial role in the retardation of recovery and recrystallization. Corresponding times for recrystallization start and finish are indicated by $\operatorname{Rs}(S)$ and $\operatorname{Rf}(S)$, respectively, in Figure 6. The dispersed particles effectively retard static recrystallization when recrystallization nucleation is already delayed by solute additions.

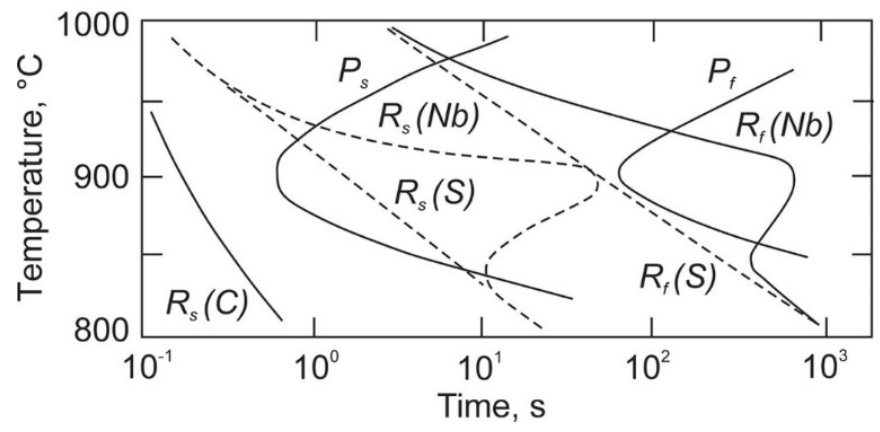

Figure 6. Effect of solid solution and precipitation on dynamic recrystallization behavior through comparison of plain-carbon $(\mathrm{C})$ and $\mathrm{Nb}$-modified $(\mathrm{Nb})$ steels. Reproduced with permission from [48], Taylor \& Francis, 1979.

\section{Tempforming}

\subsection{Microstructure}

Recently, an original approach to solute the problems of low impact toughness and high temperature of ductile-brittle transition of high-strength carbon steels has been revealed by Japanese group [3,49]. The suggested method consists of warm rolling with large reductions following the tempering of quenched martensite. The warm rolling has been suggested to carry out at a tempering temperature; thus, this processing technique has been called tempforming. In contrast to ausforming and modified ausforming, the tempforming treatment is carried out after quenching and tempering. Tempforming, therefore, is the final processing stage for technology production of rolled steel semi-products. Originally proposed for caliber bar rolling [49], tempforming has been also revealed as a promising alternative for modified ausforming applied for plate rolling [50].

The enhancement of mechanical properties is closely related to the deformation microstructure evolved in tempered martensite during large strain warm rolling. The developed microstructure in steels subjected to tempforming is commonly characterized by highly elongated grains/sub-grains along the rolling direction [50] (Figure 7a). For instance, the transverse grain and sub-grain sizes in S700MC 
steel are about $500 \mathrm{~nm}$ and $100 \mathrm{~nm}$, respectively, after warm rolling to $\varepsilon=1.5$ at $650{ }^{\circ} \mathrm{C}$ [50]. Large strain warm rolling following martensitic transformation results in lamellar-type microstructure with low- to high-angle boundaries/sub-boundaries in the tempformed steels as revealed by transmission electron microscopy using converged beam technique (Figure $7 \mathrm{~b}$ ). The warm working is usually carried out at elevated temperatures (the range of high temperature tempering). Hence, the developed microstructures do not contain high dislocation density, which remain at the level of tempered martensite, e.g., of about $8 \times 10^{14} \mathrm{~m}^{-2}$ in a high-strength low-alloyed steel [50].

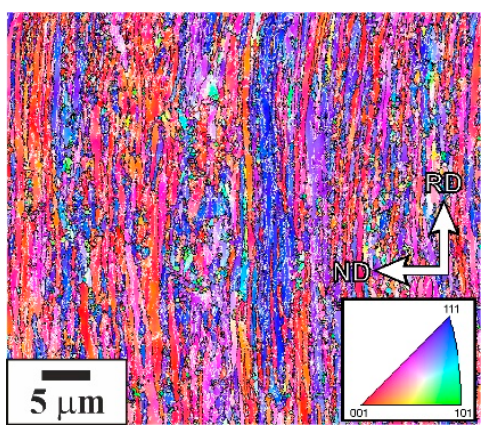

(a)

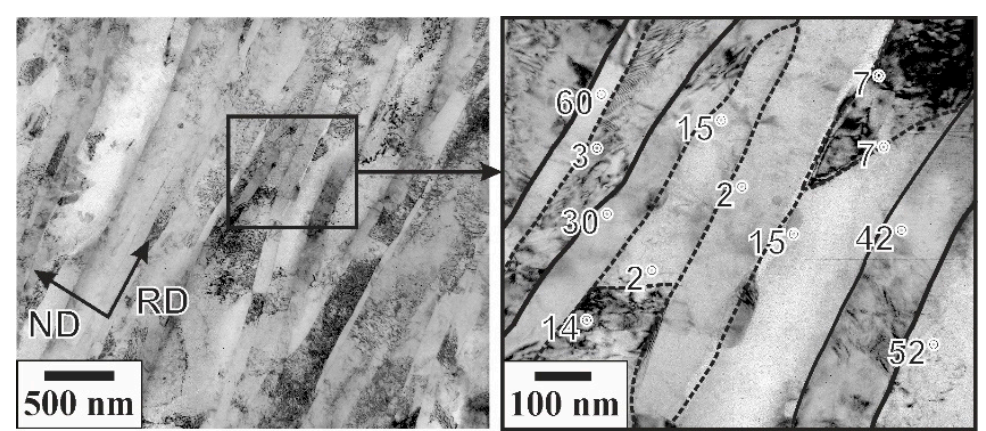

(b)

Figure 7. Elongated grains/sub-grains along the rolling direction (RD) in an S700MC steel subjected to tempforming at $650^{\circ} \mathrm{C}$ to total rolling strain of 1.5 Colors in (a)correspond to the direction along the normal direction (ND). The numbers in (b) indicate the boundary misorientations in degrees. Reproduced with permission from [50], Elsevier, 2018.

The large strain warm rolling of tempered martensite results in strong texture in the steels subjected to tempforming. Caliber bar rolling is accompanied by the development of $\alpha$-fiber of $<110>$ along the rolling direction (Figure 8) [51]. Plate rolling under conditions of warm working should lead to more complicated texture composed by a part of $\alpha$-fiber from $\{001\}<110>$ to $\{111\}<110>, \gamma$-fiber and $\theta$-fiber, i.e., $\{111\}$ and $\{001\}$ parallel with the rolling plane, respectively, [52], although the textures in tempformed steel plates have not been studied in detail. Generally, an increase in warm rolling strain during tempforming strengthens the $\alpha$-fiber in rolled rods and the partial $\alpha$-and $\gamma$-fibers in rolled plates [52]. On the other hand, the effect of tempering temperature on the texture developed seems to depend on the temperature range. Reported results suggest that there might be a temperature interval, e.g., around $600{ }^{\circ} \mathrm{C}$ for $0.6 \mathrm{C}-2 \mathrm{Si}-1 \mathrm{Cr}$ steel, that is favorable for the texture development [51].
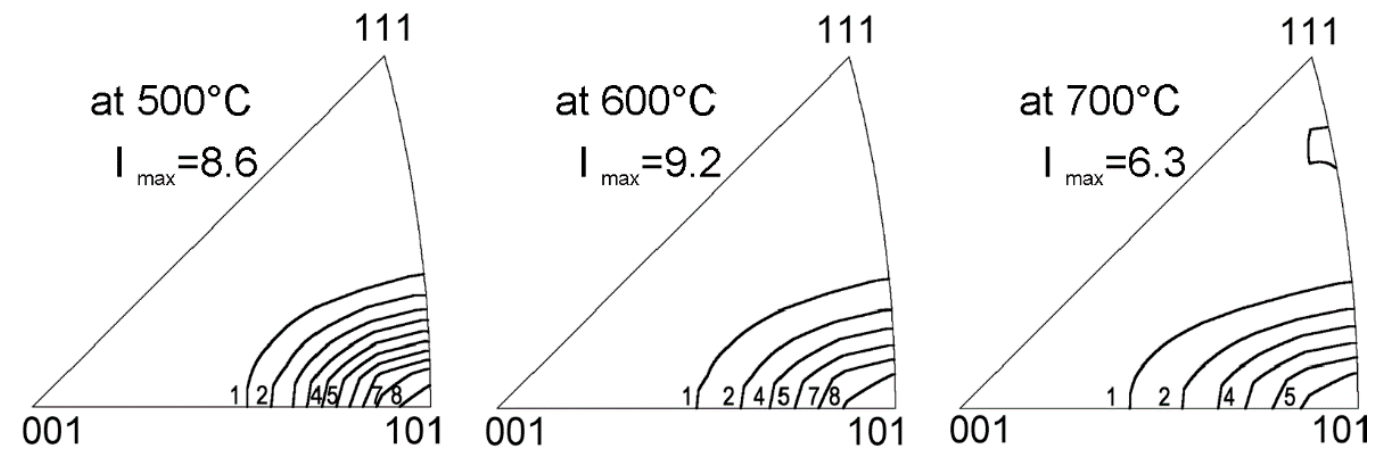

Figure 8. Inverse pole figures for the rolling direction of a $0.6 \mathrm{C}-2 \mathrm{Si}-1 \mathrm{Cr}$ steels ubjected to tempforming at indicated temperatures.

Another feature of tempformed steel microstructure inherits from tempered martensite and is associated with dispersed particles, mainly iron and alloy carbides. Plastic deformation accelerates the second-phases precipitation, leading to more complete and dispersed distribution of the particles [53]. Therefore, the tempformed steels are characterized by a homogeneous distribution of second-phase 
particles at various low-to-high-angle (sub)boundaries. The size and volume fraction of dispersed particles depends on alloying extent and processing conditions. In low-alloyed high-strength steel subjected to tempforming at $650{ }^{\circ} \mathrm{C}$, the dispersed particles are mainly $\mathrm{Cr}_{23} \mathrm{C}_{6}$-type carbides with an average size of $50 \mathrm{~nm}$ (Figure 9) [50].
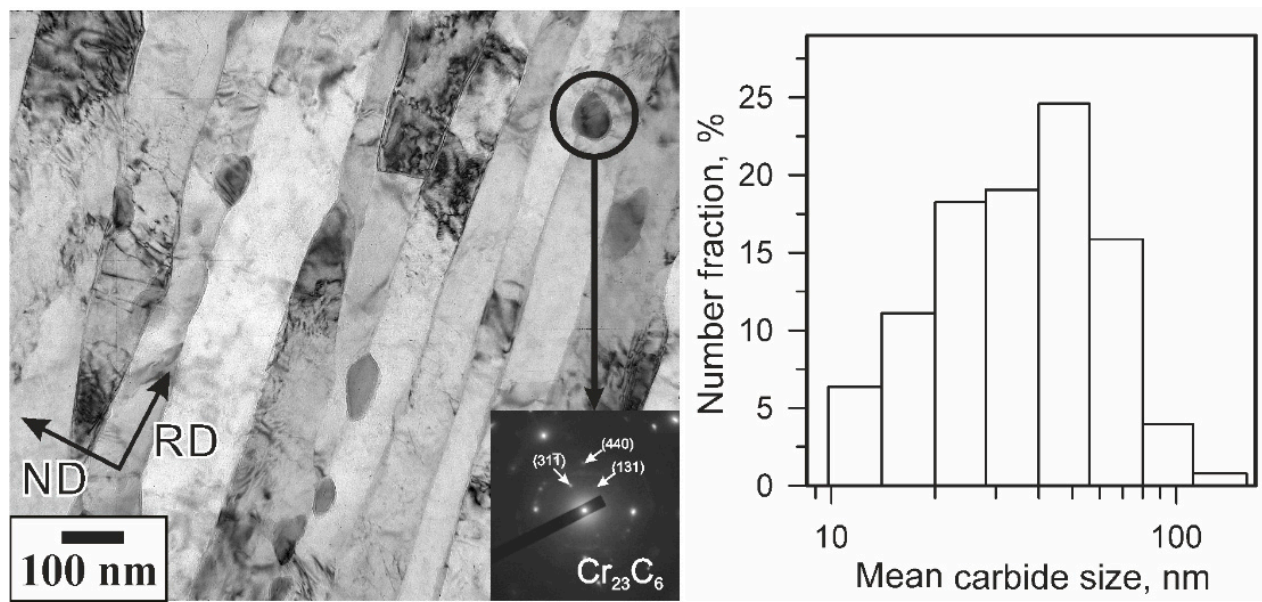

Figure 9. $\mathrm{Cr}_{23} \mathrm{C}_{6}$-type carbide particles and their size distribution in an S700MC steel subjected to tempforming at $650{ }^{\circ} \mathrm{C}$. Reproduced with permission from [50], Elsevier, 2018.

\subsection{Delamination Toughness}

High-strength low-alloyed steels subjected to tempforming possess outstanding impact toughness at lowered temperatures for the impact loading crosswise to the rolled rod axis or along the normal direction for the rolled plates (Figure 10a) [3,50]. In the latter case, the specimens for impact toughness evaluation correspond to so-called crack arrester orientation [54,55]. The tempformed steels are characterized by enhanced impact toughness as compared to conventional quenched-tempered and ausformed steels of the same chemical composition. It is worth nothing that the impact toughness of tempformed steels tends to even increase with decreasing temperature in the range down to about $-100{ }^{\circ} \mathrm{C}$. The load-displacement curves are normally characterized by general yield $\left(\mathrm{P}_{\mathrm{GY}}\right)$ followed by an increase in the load to maximum $\left(\mathrm{P}_{\mathrm{M}}\right)$ and subsequent gradual decrease in the load until the start of unstable crack propagation $\left(\mathrm{P}_{\mathrm{F}}\right)$ and then the load drop to characteristic value of crack arrest $\left(\mathrm{P}_{\mathrm{A}}\right)$ irrespective of test temperature in a wide range down to $-90^{\circ} \mathrm{C}$ (Figure 10b) [50].

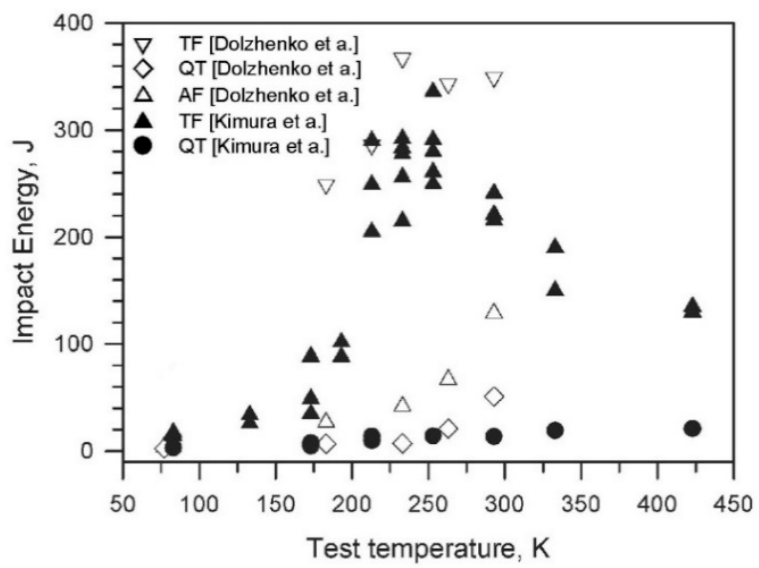

(a)

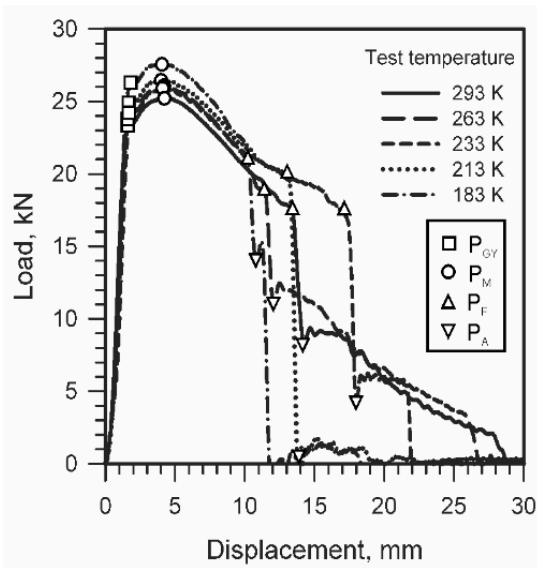

(b)

Figure 10. Variations of impact toughness of $0.4 \mathrm{C}-2 \mathrm{Si}-1 \mathrm{Cr}-1 \mathrm{Mo}$ and $\mathrm{S} 700 \mathrm{MC}$ steels subjected to tempforming (TF), or quenching-tempering (QT), or ausforming (AF) with impact test temperature (a) and load-displacement curves obtained during impact tests of tempformed S700MC (b). Reproduced with permissions from [50], Elsevier, 2018. 
The enhancement of impact toughness in the tempformed steels is attributed to delamination of the steel samples crosswise to the impact direction (Figure 11) [3]. The excellent impact properties have been reported for the laminated steel composites and discussed as a result of notch blunting because of the composite delamination [54]. The delamination nullifies the stress concentration at the crack tip, leading to gradual specimen bending accompanied by a decrease in the impact load (from $P_{M}$ to $P_{F}$ in Figure 10b) and absorbing a large energy. The break of separate bent layer results in a drop of the impact load to the crack arrest $\left(\mathrm{P}_{\mathrm{A}}\right)$, which is directly related to the next delamination event; the $\mathrm{P}_{\mathrm{A}}$ level corresponds to the bend resistance of the specimen remains.

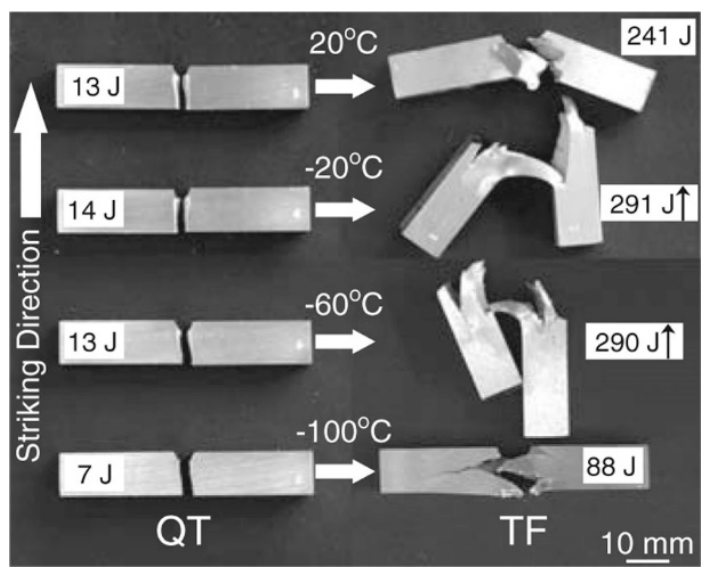

Figure 11. Impact specimens of tempformed 0.4C-2Si-1Cr-1Mo steel exhibiting delamination toughness. Reproduced with permission from [3], AAAS, 2008.

The impact toughness of notched and unnotched laminated steel composites has been almost the same [54]. The reason for delamination can be associated with internal tensile stresses, which are created ahead of the crack tip [56]. These stresses comprise about 0.2 of the peak stress concentration and act along the crack propagation direction. Delamination toughness has been also observed in a microalloyed steel with banded microstructure consisting of alternate ferrite and pearlite layers as a consequence of hot rolling [57]. The ferrite/pearlite interfaces have experienced splitting upon impact tests, changing one thick sample to a series of thin samples; an increase in the number density of ferrite/pearlite layers has thinned the delaminated segment and improved the impact toughness. Similar splitting frequently takes place in steels subjected to controlled rolling with finishing temperature in ferrite-austenite region $[31,58]$. Elongated sulfide inclusions along prior austenite grain boundaries have been considered as preferred sites for splitting crack nucleation [47].

The effect of delamination on the impact toughness can be discussed, considering the difference in coherence lengths on cleavage planes after tempforming (Figure 12) [59,60]. The coherence length of $\{001\}$ cleavage planes in the tempformed steels is highly anisotropic. The coherence length is maximal in the rolling direction and minimal in the transverse direction. Correspondingly, the cleavage fracture stress along the transverse direction $\left(\sigma_{\mathrm{C} / / \mathrm{SD}}\right.$ in Figure 12$)$ is minimal, that along the rolling direction $\left(\sigma_{\mathrm{C} / / \mathrm{RD}}\right)$ is maximal, and that at $45^{\circ}$ to rolling direction $\left(\sigma_{\mathrm{C} / 45}\right)$ is intermediate. The resolved tensile stress $\left(\sigma_{\mathrm{t}}\right)$ can be characterized by similar anisotropy, but their variation is much smaller. Therefore, the delamination fracture occurs along the cleavage plane (i) at temperatures below $\mathrm{T}_{1}$ in Figure 12, when $\sigma_{\mathrm{t} / / \mathrm{SD}}$ exceeds $\sigma_{\mathrm{C} / / \mathrm{SD}}$. This may lead to increasing the impact toughness as temperature decreases. Upon further decrease in temperature below $\mathrm{T}_{2}$, when $\sigma_{\mathrm{t} / / 45^{\circ}}$ exceeds $\sigma_{\mathrm{C} / / 45^{\circ}}$, the impact toughness decreases, because delamination happens on the cleavage planes (ii) inclined at $45^{\circ}$ to the rolling direction. Then, the brittle fracture with low absorbed energy takes place at temperatures below $\mathrm{T}_{3}$, when $\sigma_{\mathrm{t} / / \mathrm{RD}}$ exceeds $\sigma_{\mathrm{C} / / \mathrm{RD}}$. The fracture surface of specimens made of tempformed steels is commonly characterized by terracing, with brittle fracture on the terraces and ductile fracture on some steps (Figure 13) [50]. It is interesting to note that mainly brittle fracture during delamination of tempformed steels improves their impact toughness at lowered temperatures. 


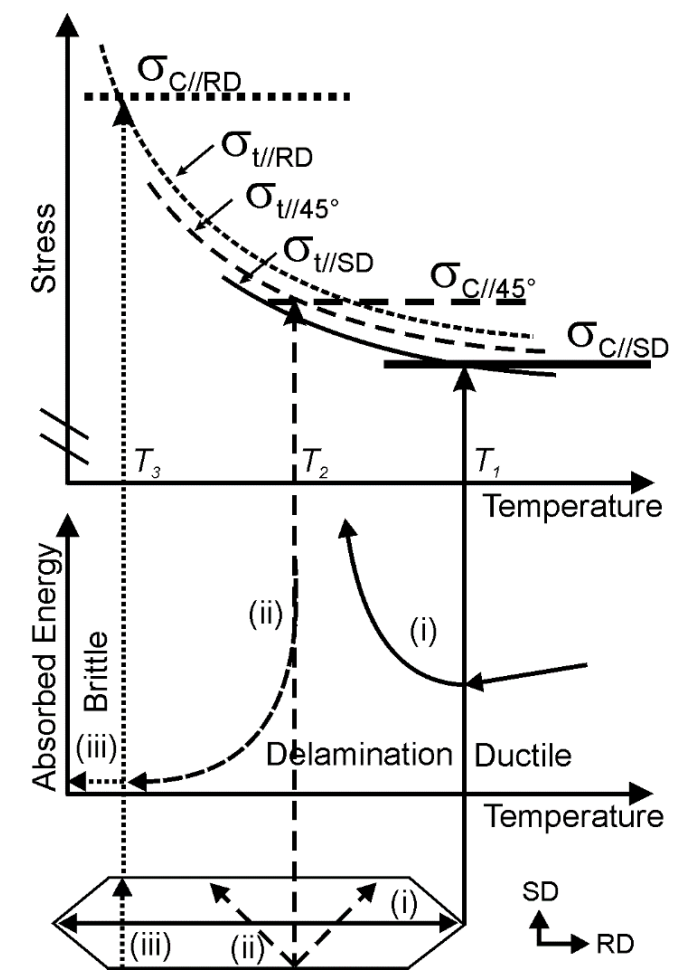

Figure 12. Modified Yoffee diagram for tempformed steels with highly elongated grains/subgrains and strong $\{110\}$ fiber texture. Reproduced with permission from [60], Elsevier, 2016.

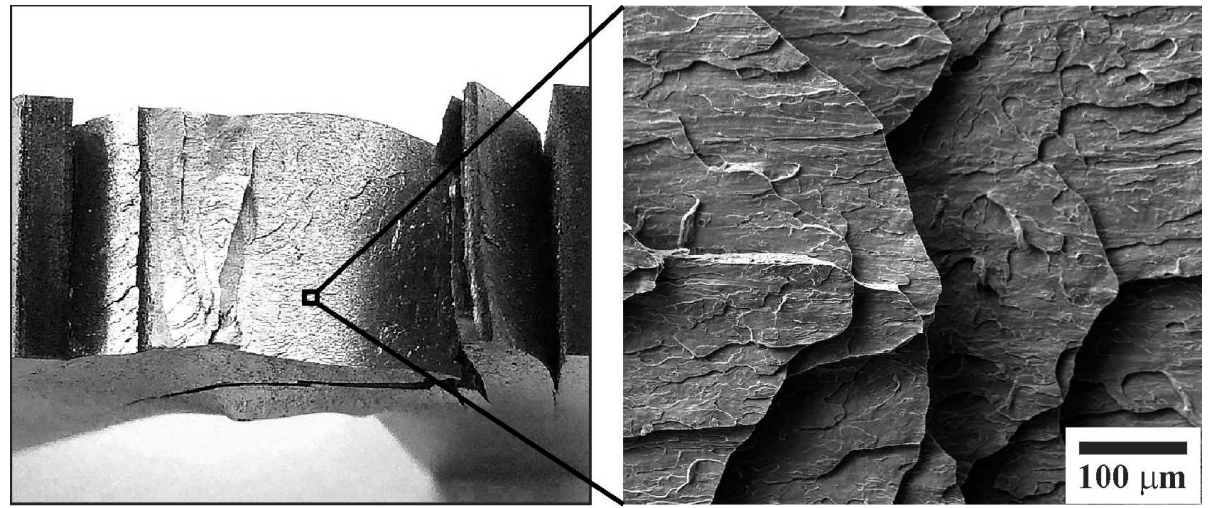

Figure 13. Terraced fracture surface of tempformed S700MC steel specimen after impact test at $20^{\circ} \mathrm{C}$. Reproduced with permission from [50], Elsevier, 2018.

Another advantage of tempforming is its suitability for steels with high concentration of harmful elements like phosphorus $[60,61]$. In contrast to structural plain carbon steels after conventional heat treatment, the phosphorus segregation has promoted delamination toughness and increased impact toughness of a $0.09 \% \mathrm{P}$ steel subjected to tempforming. On the one hand, segregations on cleavage planes arranged along the rolling direction in the tempformed steel rods/plates weakens the bonds and advances fracture, and on the other, such easy splitting results in crack blunting and increases the impact toughness.

It is worth noting that impact toughness of tempformed steels depends significantly on the loading direction. The microstructural anisotropy of highly elongated (after bar rolling) or flattened (after plate rolling) microstructure results in corresponding mechanical anisotropy. In contrast to rolled bars/rods, when all impact direction crosswise to the rolling direction are kinds of crack arrester orientations, the impact load along only normal direction corresponds to crack arrester orientation for rolled plates. Thus, tempformed plates exhibit outstanding impact toughness in crack arrester orientation, whereas 
their impact toughness in the case of loading direction along transverse direction (crack divider orientation [55]) is much lower and may rank below that of ordinary thermo-mechanically treated steel [50]. It is obvious that impact toughness in crack delamination orientation [55] of the tempformed steels is quite low, which is, probably, the major drawback of tempforming treatment.

\subsection{Strengthening}

The development of lamellar microstructure with the transverse grain size well below $1 \mu \mathrm{m}$ along with rather high dislocation density in grain/sub-grain interior and uniform dispersion of second-phase particles (mainly carbides) in tempformed steels result in significant strengthening [3,50]. For instance, the yield strength of high-strength low-alloyed steel subjected to tempforming at $650{ }^{\circ} \mathrm{C}$ approaches $1100 \mathrm{MPa}$, which is greater by almost $200 \mathrm{MPa}$ than that in the ausformed state (Figure 14) [50]. The effect of grain size (D) on the yield strength $\left(\sigma_{0.2}\right)$ is generally expressed by the Hall-Petch relationship [62,63],

$$
\sigma_{0.2}=\sigma_{0}+k_{\mathrm{y}} \mathrm{D}^{-0.5}
$$

where $\sigma_{0}$ is the strength of the same material with infinite grain size and $k_{\mathrm{y}}$ is the grain boundary strengthening factor. Taking $\sigma_{0}=70 \mathrm{MPa}$ and $k_{\mathrm{y}}=240 \mathrm{MPa} \mu \mathrm{m}^{0.5}$ for low-alloyed ferrite [64-66] and effective grain size of $1 \mu \mathrm{m}$, the grain size strengthening of tempformed steel comprises about $310 \mathrm{MPa}$. The dislocation strengthening $\left(\Delta \sigma_{\rho}\right)$ is commonly expressed by Taylor-type equation [67],

$$
\Delta \sigma_{\rho}=\alpha \mathrm{Gb} \cdot \rho^{0.5},
$$

where $\alpha$ is the numerical factor of about 0.9 [68], G is the shear modulus ( $81,000 \mathrm{MPa}$ for low-alloyed steels [69]), $\mathrm{b}$ is the Burgers vector $\left(2.5 \times 10^{-10} \mathrm{~m}^{-1}\right.$ in ferrite [69]) and $\rho$ is the dislocation density. Thus, the dislocation strengthening of ausformed steels with $\rho=8 \times 10^{14} \mathrm{~m}^{-2}$ can be as high as $515 \mathrm{MPa}$. The dispersion strengthening $\left(\Delta \sigma_{\mathrm{OR}}\right)$ is usually expressed by Orowan relationship [70],

$$
\Delta \sigma_{\mathrm{OR}}=0.4 \mathrm{MGb} \cdot(\pi \lambda)^{-1} \cdot(1-v)^{-0.5} \cdot \ln (0.8 \mathrm{~d} / \mathrm{b}),
$$

where $\mathrm{M}$ is the Taylor factor, $\mathrm{d}$ is the mean particle size, $\lambda$-is the interparticle distance, which can be evaluated as $\lambda=\mathrm{d} \cdot\left(0.36 \mathrm{~F}_{\mathrm{V}}{ }^{-0.5}-1\right)$ for randomly distributed particles with volume fraction of $\mathrm{F}_{\mathrm{V}}$ [71]. Taking the latter of about $0.8 \%$ for particles located in grain/sub-grain interiors and at low-angle dislocation sub-boundaries of high-strength low-alloyed steels and $\mathrm{d}=50 \mathrm{~nm}$, the dispersed particles provide about $250 \mathrm{MPa}$ strength increment. Then, assuming that the strengthening mechanisms above are independent and linear additive [72,73], the calculated yield strength comprises $1075 \mathrm{MPa}$ that is almost the same with experimental one (Figure 14). The speculation above suggests that the dislocation strengthening is the major contributor to the strengthening of high-strength low-alloyed steels subjected to tempforming.

It should be noted that an increase in the yield strength after tempforming is not accompanied by a decrease in ductility and the upper-shelf energy of impact toughness as frequently observed in the steels processed by ausforming/modified ausforming [51]. This beneficial effect of tempforming on the mechanical properties seems to be attributed to the development of a kind of ultrafine grained microstructure. The ultrafine grained metals and alloys have been frequently reported to possess a unique combination of high strength and plasticity [65,74-76]. The grain refinement down to sub-micrometer scale may strengthen metallic materials without a degradation of plasticity.

The effect of hot working of austenite on the microstructure and properties of tempformed steel has not been studied in sufficient detail, although a decrease in the prior austenite grain size has been shown to be favorable for ductility and toughness of steels subjected to tempforming [77]. After tempforming, the transverse size of largely elongated grains/sub-grains and the second-phase particle dispersion depend mainly on the tempforming conditions, i.e., tempering time/temperature and subsequent strain, irrespective of the size of prior austenite grains. On the other hand, the size of 
prior austenite grains should affect the size of martensite packets [77]. Generally, the refinement of microstructural elements promotes plasticity. Moreover, the dislocation substructure in the hot worked austenite is expected to have a beneficial effect on the mechanical properties of tempformed steels similar to that in the ausforming and modified ausforming.

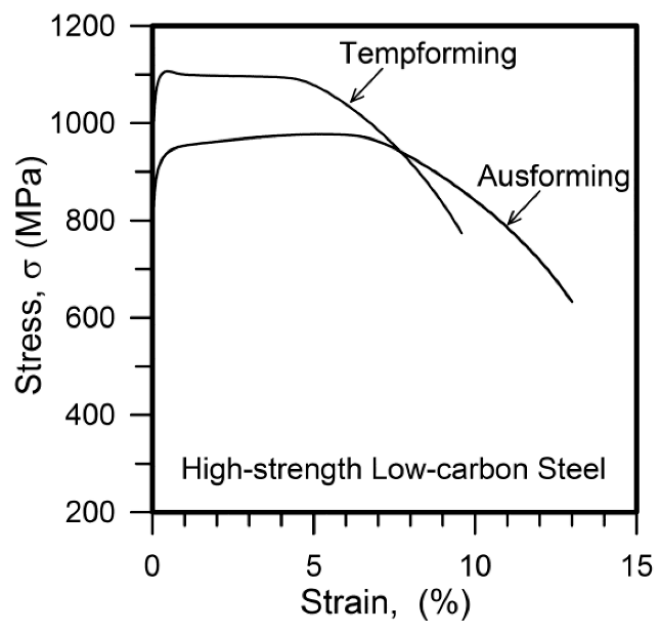

Figure 14. Tensile stress-strain curves for a high-strength low-carbon steel processed by tempforming or ausforming. Reproduced with permission from [50], Elsevier, 2018.

\subsection{Effect of Tempforming Temperature}

Tempering temperature controls the softening of tempered martensite and the developed microstructure, i.e., dislocation density, lath size (for the case of lath martensite), size and distribution of second-phase particles [78]. Subsequent rolling at the tempering temperature is accompanied by dynamic recovery of tempered dislocation substructure and leads to the elongation or pancaking of microstructural elements, grains/sub-grains, along the rolling direction [59]. The transverse grain/sub-grain size commonly reduces while the dislocation and particle densities increase with a decrease in rolling temperature. Thus, warm rolling following tempering increases the yield strength of tempered steel that is associated with characteristic changes in the microstructural parameters. On the other hand, the effect of tempforming temperature on the ultimate tensile strength substantially depends on the alloying extent. The ultimate tensile strength increases by tempforming in steels with relatively small carbon content, whereas that can be even decreased after tempforming of steels with rather high carbon content of about $0.6 \%$ (Figure 15) [51,79].

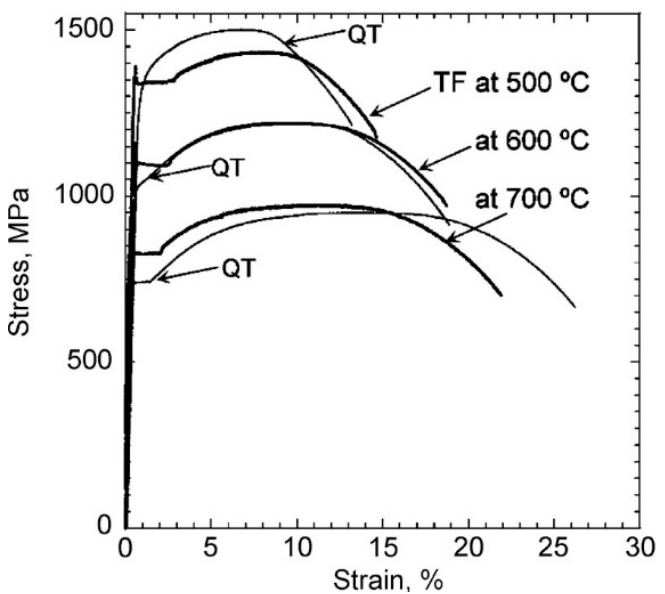

(a)

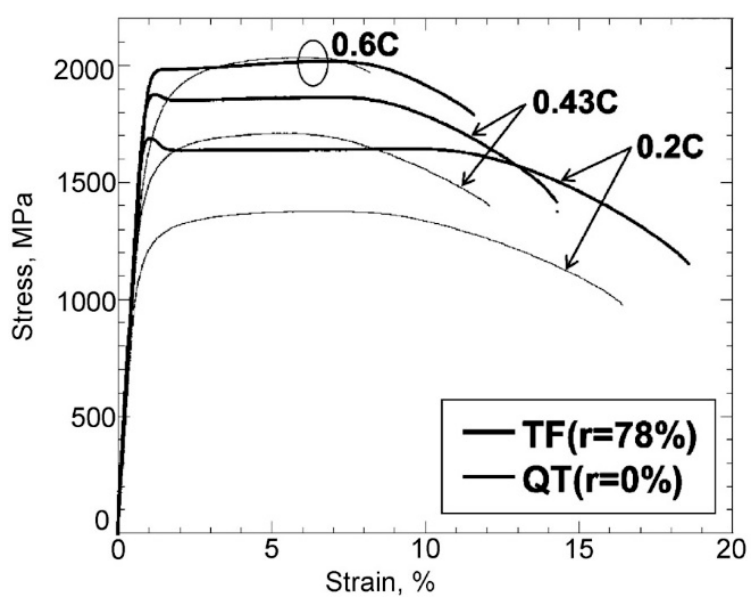

(b)

Figure 15. Tensile stress-strain curves of $0.6 \mathrm{C}-2 \mathrm{Si}-1 \mathrm{Cr}$ steel [51] (a) and (0.2-0.6)C-2Si-1Cr-1Mo steels (b) subjected to tempforming (TF) or conventional quenching-tempering (QT). 
A decrease in tempforming temperature enhances the delamination along the rolling plane, increasing the impact toughness at lowered temperatures (Figure 16) [51,80]. Correspondingly, an increase tempering temperature weakens the effect of tempforming on the impact toughness. The latter increases with an increase in tempering temperature and does not significantly change by subsequent rolling. On the other hand, tempforming at elevated temperatures results in increased upper-shelf energy, although advantage of tempforming at elevated temperatures over conventional quenching and tempering is not so pronounced. Therefore, in order to make the best use of tempforming, it should be carried out at relatively low tempering temperatures, when the effect of delamination toughness can be achieved in combination with a high strength.

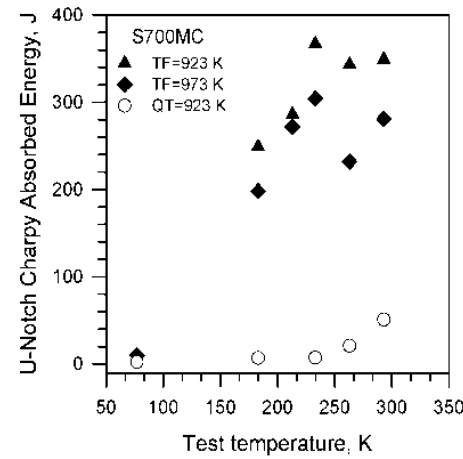

(a)

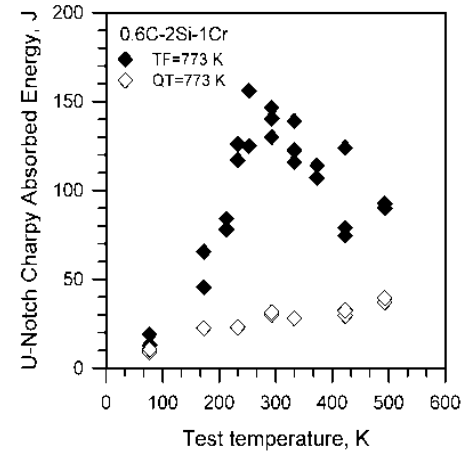

(b)

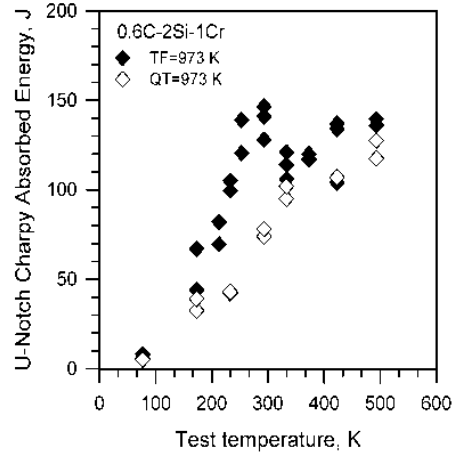

(c)

Figure 16. Effect of tempforming (TF) at different temperatures on the impact toughness of S700MC (a) and $0.6 \mathrm{C}-2 \mathrm{Si}-1 \mathrm{Cr}(\mathbf{b}, \mathbf{c})$ steels in comparison with ordinary quenching-tempering (QT).

\subsection{Carbon Effect}

The first impressive results on the combination of high strength and impact toughness achieved by tempforming have been obtained in medium carbon $(0.4 \%)$ high-strength steel $[3,49]$. Then, Kimura et al. have carried out a series of studies, using steels with $0.2 \% \mathrm{C}$ to $0.6 \% \mathrm{C}[51,59-61,79,81]$. The obtained results can be summarized as follows. The upper-shelf energy in the steels subjected to tempforming increases with a decrease in carbon content (Figure 17) [79]. The temperature of ductile-brittle transition in the tempformed steels also decreases with a decrease in carbon content (Figure 17). It is worth noting that the same tendency for the upper-shelf energy dependence on carbon is observed in these steels after conventional quenching and tempering.

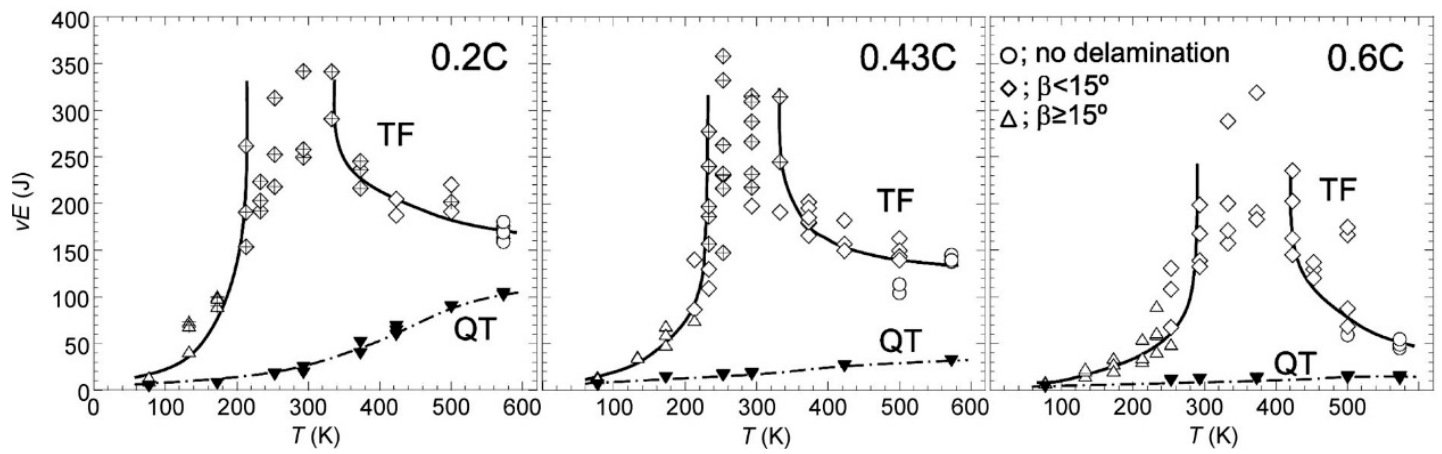

Figure 17. Effect of carbon content on impact toughness of high-strength steels subjected to tempforming (TF) or conventional quenching-tempering (QT).

The carbon effect on the strengthening of steels subjected to tempforming is illustrated in Figure 17. It is clearly seen that the strengthening effect of tempforming diminishes with increasing the carbon content. Therefore, proficiency of tempforming in improving the mechanical properties of carbon steels decreases as the carbon content increases. The effect of tempforming temperature on the impact 
toughness at low temperature is also more pronounced in the steels with low carbon content (Figure 15b), although the tempforming effect on the properties of steels with various alloying extent should be further clarified. It can be concluded that tempforming is very effective thermo-mechanical treatment for obtaining high-strength medium carbon steels with high impact toughness at lowered temperatures that expand significantly the service conditions of these steels towards low temperature applications. On the other hand, concurrent increase in impact toughness and strength of low-alloyed steels opens new perspectives for high-strength low-alloyed steels as structural material for crucial applications.

\section{Summary and Perspectives}

Tempforming is a very promising thermo-mechanical treatment, particularly for high-strength carbon steels. Conventional heat treatment, i.e., quenching and tempering, is very effective for producing the steels for various structural applications with appropriate strength level, which is controlled by tempering conditions. However, exploitation of such steels processed in high strength state under conditions of lowered temperature requires solving a problem of low impact toughness, which is associated with relatively high ductile-brittle transition temperature, leading frequently to brittle fracture at ambient temperatures. Ordinary ausforming and/or modified ausforming impose certain conditions on the alloying design of steels, which can be processed. The austenite in these steels should possess rather slow transformation kinetics in the temperature range between $\mathrm{Ar}_{1}$ and Ms, or should be stable against discontinuous recrystallization at temperatures above $\mathrm{Ar}_{3}$. Moreover, corresponding temperature intervals should be sufficiently wide to use conventional rolling technology. Hence, various carbon steels are far beyond the required conditions and can be hardly improved by ausforming/modified ausforming.

In contrast to ordinary approach for improving the impact toughness owing to enhanced ductile fracture, tempforming utilizes brittle fracture in order to increase impact toughness. The brittle delamination in tempformed steels blocks the crack propagation across the rolled steel semi-product, resulting in high impact toughness even at low temperatures. It is important to note that tempforming increases the impact toughness without any degradation of strength. High-strength low-alloyed steels are other perspective candidates for processing by tempforming. Tempforming of these steels provides simultaneous increase in both impact toughness and strength. It is worth noting that impact toughness after tempforming increases, especially, at lowered temperatures that is commonly problem domain for high-strength carbon steels processed by ordinary quenching and tempering. Variety of high-strength steels applicable to tempforming makes this treatment very attractive for steel production, although the benefits and disadvantage of tempforming for steels with different alloying design are not clear yet and require further investigations.

Current studies on tempforming of hot worked steels suggest an approach for further improvement of mechanical properties of high-strength steels. More beneficial combination of high strength and impact toughness can be achieved by thermo-mechanical treatment combining the grain refinement in austenite followed by tempforming of tempered martensite. The refinement of prior austenite grains as a result of dynamic recrystallization during hot to warm working is expected to accelerate the formation of desired ultrafine lamellar microstructure during subsequent tempforming. In turn, reduction of rolling strain during tempforming increases productivity of the process and allows us widening the diversity of processed steels owing to variety of applicable regimes.

Author Contributions: Conceptualization, R.K. and A.B.; software, A.D.; formal analysis, A.D.; resources, A.D. and A.B.; writing — original draft preparation, A.B.; writing—review and editing, R.K.; supervision, R.K.; project administration, A.B.; funding acquisition, R.K. All authors have read and agreed to the published version of the manuscript.

Funding: This research was funded by the Russian Science Foundation, Agreement No. 20-19-00497.

Acknowledgments: Authors are grateful to the personnel of the Joint Research Center, Technology \& Materials, Belgorod State University, for their assistance with instrumental analysis.

Conflicts of Interest: The authors declare no conflict of interest. 


\section{References}

1. Morris, J.W., Jr. Stronger, tougher steels. Science 2008, 320, 1022-1023. [CrossRef]

2. Morris, J.W., Jr. The influence of grain size on the mechanical properties of steel. In Proceedings of the International Symposium on Ultrafine Grained Steels, Fukuoka, Japan, 20-22 September 2001; Takaki, S., Maki, T., Eds.; Iron and Steel Institute of Japan: Tokyo, Japan, 2001; pp. 34-41.

3. Kimura, Y.; Inoue, T.; Yin, F.; Tsuzaki, K. Inverse temperature dependence of toughness in an ultrafine grain-structure steel. Science 2008, 320, 1057-1060. [CrossRef] [PubMed]

4. Knott, J.F. Fundamentals of Fracture Mechanics; The Butterworth Group: London, UK, 1973.

5. Hertzberg, R.W.; Vinci, R.P.; Hertzberg, J.L. Deformation and Fracture Mechanics of Engineering Materials, 5th ed.; Wiley: Hoboken, NJ, USA, 2013.

6. Odnobokova, M.V.; Kipelova, A.Y.; Belyakov, A.N.; Kaibyshev, R.O. Mechanical behavior and brittle-ductile transition of high chromium martensitic steel. Phys. Met. Metallogr. 2016, 117, 390-398. [CrossRef]

7. Hirth, J.P.; Lotte, J. Theory of Dislocations, 2nd ed.; Wiley: Hoboken, NJ, USA, 1982.

8. Rybin, V.V. Large Strain Deformations and Fracture of Materials; Metallurgiya: Moscow, Russia, 1986.

9. Romanov, A.E.; Vladimirov, V.I. Disclinations in crystalline solids. In Dislocations in Solids; Nabarro, F.R.N., Ed.; Elsevier: Amsterdam, The Nederlands, 1992; Volume 9.

10. Mishnev, R.; Dudova, N.; Dudko, V.; Kaibyshev, R. Impact toughness of a 10\% Cr steel with high boron and low nitrogen contents. Mater. Sci. Eng. A 2018, 730, 1-9. [CrossRef]

11. Morris, J.W., Jr. Comments on the microstructure and properties of ultrafine grained steel. ISIJ Int. 2008, 48, 1063-1070. [CrossRef]

12. Schmatz, D.J.; Zackay, V.F. Development of ultra-high steels by deformation of undercooled austenite. Met. Sci. Heat Treat. 1960, 2, 417-418. [CrossRef]

13. Kula, E.B.; Dhosi, J.M. Effect of deformation prior to transformation on the mechanical properties of steel 4340. Met. Sci. Heat Treat. 1961, 3, 225-229. [CrossRef]

14. Bernshtein, M.L. Thermomechanical Treatment of Metals and Alloys; Metallurgiya: Moscow, Russia, 1968.

15. Mukherjee, J.K. Thermomechanical ausforming technique for producing substitute ultra high strength steels. In Proceedings of the Symposium on Metallurgy of Substitute Ferrous \& Non-Ferrous Alloys, Jamshedpur, India, 27-30 April 1966; National Metallurgy Laboratory: Jamshedpur, India, 1966; pp. 156-161. Available online: http://eprints.nmlindia.org/3137/ (accessed on 28 October 2020).

16. Sakhin, S.I.; Sokolov, O.G. Strengthening of steels 30KhNMA and 30KhGSNA. Met. Sci. Heat Treat. 1962, 4, 8-11.

17. Schaller, F.W.; Schmatz, D.J. The inheritance of defects by martensite. Acta Metall. 1963, 11, $1193-1194$. [CrossRef]

18. Seo, S.-W.; Jung, G.-S.; Lee, J.S.; Bae, C.M.; Bhadeshia, H.K.D.H.; Suh, D.-W. Ausforming of medium carbon steel. Mater. Sci. Technol. 2015, 31, 436-442. [CrossRef]

19. Strife, J.R.; Carr, M.J.; Ansell, G.S. The effect of austenite prestrain above the Md temperature on the martensitic transformation in Fe-Ni-Cr-C alloys. Metall. Trans. A 1977, 8A, 1471-1484. [CrossRef]

20. Tian, J.; Chen, G.; Xu, Y.; Jiang, Z.; Xu, G. Comprehensive analysis of the effect of ausforming on the martensite start temperature in a Fe-C-Mn-Si medium-carbon high-strength bainite steel. Metall. Mater. Trans. A 2019, 50, 4541-4549. [CrossRef]

21. Eres-Castellanos, A.; Caballero, F.G.; Garcia-Mateo, C. Stress or strain induced martensitic and bainitic transformations during ausforming processes. Acta Mater. 2020, 189, 60-72. [CrossRef]

22. Hu, H.; Xu, G.; Dai, F.; Tian, J.; Chen, G. Critical ausforming temperature to promote isothermal bainitic transformation in prior-deformed austenite. Mater. Sci. Technol. 2019, 35, 420-428. [CrossRef]

23. Tomita, Y. Development of fracture toughness of ultrahigh strength, medium carbon, low alloy steels for aerospace applications. Int. Mater. Rev. 2000, 45, 27-37. [CrossRef]

24. Yen, C.M.; Stickels, C.A. Lamellate fracture in 5150 steel processed by modified ausforming. Metall. Trans. 1970, 1, 3037-3047.

25. Tomita, Y. Low-temperature improvement of mechanical properties of AISI 4340 steel through high-temperature thermomechanical treatment. Metall. Trans. A 1991, 22, 1093-1102. [CrossRef]

26. Gulyaev, A.I.; Shigarev, A.S. Effect of thermomechanical treatment on fine structure. Met. Sci. Heat Treat. 1963, 5, 191-194. [CrossRef] 
27. Hyspecka, I.; Balusek, J.; Mazanec, K. Hutnicke listy. Kovove Mater. 1963, No 2, 251-255.

28. Rakhshtadt, A.G. Spring Alloys; Metallurgiya: Moscow, Russia, 1965.

29. Bernshtein, M.L. High temperature thermomechanical treatment of machine construction steels. Met. Sci. Heat Treat. 1966, 7, 446-448. [CrossRef]

30. Tomita, Y. Low temperature mechanical properties of quenched and tempered 0.4C-Ni-Cr-Mo steel after controlled rolling. Mater. Sci. Technol. 1988, 4, 613-620. [CrossRef]

31. Thaulow, C.; Paauw, A.J.; Gunleiksrud, A.; Troset, J. Fracture mechanical properties in controlled rolled CMn Thermomechanically treated steels with splittings. Eng. Fract. Mech. 1986, 24, 263-276. [CrossRef]

32. Ohmori, M.; Kawamata, K. Strengthening of steels by modified ausforming. Bull. JSME 1978, 21, 359-366. [CrossRef]

33. Watanabe, S.; Araki, T.; Miyaji, H. Strengthening of alloys by ausforming. Tetsu-to-Hagane 1969, 55, 797-812. [CrossRef]

34. Jonas, J.J.; Sellars, C.M.; Tegart, W.J.M. Strength and structure under hot-working conditions. Metall. Rev. 1969, 14, 1-24. [CrossRef]

35. Sakai, T.; Jonas, J.J. Dynamic recrystallization-Mechanical and microstructural considerations. Acta Metall. 1984, 32, 189-209. [CrossRef]

36. Sakai, T.; Ohashi, M. Dislocation substructures developed during dynamic recrystallization in polycrystalline nickel. Mater. Sci. Technol. 1990, 6, 1251-1257. [CrossRef]

37. Huang, K.; Logé, R.E. A review of dynamic recrystallization phenomena in metallic materials. Mater. Des. 2016, 111, 548-574. [CrossRef]

38. Sakai, T.; Belyakov, A.; Kaibyshev, R.; Miura, H.; Jonas, J.J. Dynamic and post-dynamic recrystallization under hot, cold and severe plastic deformation conditions. Prog. Mater. Sci. 2014, 60, 130-207. [CrossRef]

39. Maki, T.; Akasaka, K.; Okuno, K.; Tamura, I. Dynamic recrystallization of austenite in 18-8 stainless steel and 18Ni maraging steel. Trans. Iron Steel Ins. Jpn. 1982, 22, 253-261. [CrossRef]

40. Belyakov, A.; Sakai, T.; Miura, H.; Kaibyshev, R. Grain refinement under multiple warm deformation in 304 type austenitic stainless steel. ISIJ Int. 1999, 39, 592-599. [CrossRef]

41. Jafari, M.; Najafizadeh, A. Correlation between Zener-Hollomon parameter and necklace DRX during hot deformation of 316 stainless steel. Mater. Sci. Eng. A 2009, 501, 16-25. [CrossRef]

42. Beladi, H.; Cizek, P.; Hodgson, P.D. On the characteristics of substructure development through dynamic recrystallization. Acta Mater. 2010, 58, 3531-3541. [CrossRef]

43. Murty, S.V.S.; Torizuka, S.; Nagai, K.; Kitai, T.; Kogo, Y. Effect of initial grain size on evolved ferrite grain size during high $Z$ large strain deformation. Mater. Sci. Technol. 2010, 26, 879-885. [CrossRef]

44. Belyakov, A.; Tikhonova, M.; Yanushkevich, Z.; Kaibyshev, R. Regularities of grain refinement in an austenitic stainless steel during multiple warm working. Mater. Sci. Forum 2013, 753, 411-416. [CrossRef]

45. Yanushkevich, Z.; Lugovskaya, A.; Belyakov, A.; Kaibyshev, R. Deformation microstructures and tensile properties of an austenitic stainless steel subjected to multiple warm rolling. Mater. Sci. Eng. A 2016, 667, 279-285. [CrossRef]

46. Tikhonova, M.; Belyakov, A.; Kaibyshev, R. Strain-induced grain evolution in an austenitic stainless steel under warm multiple forging. Mater. Sci. Eng. A 2013, 564, 413-422. [CrossRef]

47. Tanaka, T. Controlled rolling of steel plate and strip. Int. Mater. Rev. 1981, 26, 185-212. [CrossRef]

48. Jonas, J.J.; Weiss, I. Effect of precipitation on recrystallization in microalloyed steels. Met. Sci. 1979, 13, 238-246. [CrossRef]

49. Kimura, Y.; Inoue, T.; Yin, F.; Sitdikov, O.; Tsuzaki, K. Toughening of a $1500 \mathrm{MPa}$ class steel through formation of an ultrafine fibrous grain structure. Scripta Mater. 2007, 57, 465-468. [CrossRef]

50. Dolzhenko, A.; Yanushkevich, Z.; Nikulin, S.A.; Belyakov, A.; Kaibyshev, R. Impact toughness of an S700MC-type steel: Tempforming vs ausforming. Mater. Sci. Eng. A 2018, 723, 259-268. [CrossRef]

51. Kimura, Y.; Inoue, T.; Yin, F.; Tsuzaki, K. Delamination toughening of ultrafine grain structure steels processed through tempforming at elevated temperatures. ISIJ Int. 2010, 50, 152-161. [CrossRef]

52. Kestens, L.A.I.; Pirgazi, H. Texture formation in metal alloys with cubic crystal structures. Mater. Sci. Technol. 2016, 32, 1303-1315. [CrossRef]

53. Weiss, I.; Jonas, J.J. Interaction between recrystallization and precipitation during the high temperature deformation of HSLA steels. Metal. Trans. A 1979, 10, 831-840. [CrossRef] 
54. Kum, D.W.; Oyama, T.; Wadsworth, J.; Sherby, O.D. The impact properties of laminated composites containing ultrahigh carbon (UHC) steels. J. Mech. Phys. 1983, 31, 173-186. [CrossRef]

55. Venkateswara Rao, K.T.; Yu, W.; Ritchie, R.O. Cryogenic toughness of commercial aluminum-lithium alloys: Role of delamination toughening. Metall. Trans. A 1989, 20, 485-497. [CrossRef]

56. Cook, J.; Gordon, J.E.; Evans, C.C.; Marsh, D.M. A mechanism for the control of crack propagation in all-brittle systems. Proc. R. Soc. Lond. A 1964, 282, 508-520.

57. Shanmugam, P.; Pathak, S.D. Some studies on the impact behavior of banded microalloyed steel. Eng. Fract. Mech. 1996, 53, 991-1005. [CrossRef]

58. Faucher, B.; Dogan, B. Evaluation of the fracture toughness of hot-rolled low-alloy Ti-V plate steel. Metall. Trans. A 1988, 19, 505-516. [CrossRef]

59. Kimura, Y.; Inoue, T. Influence of warm tempforming on microstructure and mechanical properties in an ultrahigh-strength medium-carbon low-alloy steel. Metall. Mater. Trans. A 2013, 44, 560-576. [CrossRef]

60. Min, X.; Kimura, Y.; Kimura, T.; Tsuzaki, K. Delamination toughening assisted by phosphorus in medium-carbon low-alloy steels with ultrafine elongated grain structures. Mater. Sci. Eng. A 2016, 649, 135-145. [CrossRef]

61. Jafari, M.; Kimura, Y.; Tsuzaki, K. Enhancement of upper shelf energy through delamination fracture in 0.05 pct P doped high-strength steel. Metall. Mater. Trans. A 2012, 43, 2453-2465. [CrossRef]

62. Hall, E.O. The deformation and ageing of mild steel: III discussion of results. Proc. Phys. Soc. Lond. 1951, 64, 747-753. [CrossRef]

63. Petch, N.J. The cleavage strength of polycrystals. J. Iron Steel Inst. 1953, 174, 25-28.

64. Armstrong, R.; Codd, I.; Douthwaite, R.M.; Petch, N.J. The plastic deformation of polycrystalline aggregates. Philos. Mag. 1962, 7, 45-58. [CrossRef]

65. Tsuji, N.; Okuno, S.; Koizumi, Y.; Minamino, Y. Toughness of ultrafine grained ferritic steels fabricated by ARB and annealing process. Mater. Trans. 2004, 45, 2272-2281. [CrossRef]

66. Belyakov, A.; Tsuzaki, K.; Kimura, Y.; Mishima, Y. Tensile behaviour of submicrocrystalline ferritic steel processed by large-strain deformation. Phil. Mag. Lett. 2009, 89, 201-212. [CrossRef]

67. Taylor, G.I. The mechanism of plastic deformation of crystals. Part I.-Theoretical. Proc. R. Soc. Lond. Ser. Contain. Pap. Math. Phys. Character 1934, 145, 362-387.

68. Akama, D.; Tsuchiyama, T.; Takaki, S. Evaluation of dislocation density in cold-worked iron as measured via X-ray diffractometry. Zair. J. Soc. Mater. Sci. Jpn. 2017, 66, 522-527. [CrossRef]

69. Frost, H.J.; Ashby, M.F. Deformation Mechanism Maps; Pergamon Press: Oxford, UK, 1982.

70. Harrell, T.J.; Topping, T.D.; Wen, H.; Hu, T.; Schoenung, J.M.; Lavernia, E.J. Microstructure and strengthening mechanisms in an ultrafine grained Al-Mg-Sc alloy produced by powder metallurgy. Metall. Mater. Trans. A 2014, 45, 6329-6343. [CrossRef]

71. Humphreys, F.J.; Hatherly, M. Recrystallization and Related Annealing Phenomena, 2nd ed.; Elsevier: Oxford, UK, 2004.

72. Hughes, D.A.; Hansen, N. Microstructure and strength of nickel at large strains. Acta Mater. 2000, 48, 2985-3004. [CrossRef]

73. Zhang, X.; Godfrey, A.; Huang, X.; Hansen, N.; Liu, Q. Microstructure and strengthening mechanisms in cold-drawn pearlitic steel wire. Acta Mater. 2011, 59, 3422-3430. [CrossRef]

74. Valiev, R. Materials science: Nanomaterial advantage. Nature 2002, 31, 887-889. [CrossRef] [PubMed]

75. Stolyarov, V.V.; Valiev, R.Z.; Zhu, Y.T. Enhanced low-temperature impact toughness of nanostructured Ti. App. Phys. Lett. 2006, 88, 041905. [CrossRef]

76. Estrin, Y.; Vinogradov, A. Extreme grain refinement by severe plastic deformation: A wealth of challenging science. Acta Mater. 2013, 61, 782-817. [CrossRef]

77. Kimura, Y.; Inoue, T. Influence of prior-austenite grain structure on the mechanical properties of ultrafine elongated grain structure steel processed by warm tempforming. ISIJ Int. 2015, 55, 1762-1771. [CrossRef]

78. Fedorova, I.; Kostka, A.; Tkachev, E.; Belyakov, A.; Kaibyshev, R. Tempering behavior of a low nitrogen boron-added 9\%Cr steel. Mater. Sci. Eng. A 2016, 662, 443-455. [CrossRef]

79. Kimura, Y.; Inoue, T. Influence of carbon content on toughening in ultrafine elongated grain structure steels. ISIJ Int. 2015, 55, 1135-1144. [CrossRef] 
80. Dolzhenko, A.; Yanushkevich, Z.; Kopteva, K.; Belyakov, A.; Kaibyshev, R. Effect of Tempforming Temperature on the Microstructure and Mechanical Properties of a High-Strength Low-Carbon Steel. In Metal 2019, Proceedings of the 28th International Conference on Metallurgy and Materials, Brno, Czech Republic, 22-24 May 2019; Tanger Ltd.: Ostrava, Czech Republic, 2019; pp. 632-637.

81. Kimura, Y.; Inoue, T. Mechanical property of ultrafine elongated grain structure steel processed by warm tempforming and its application to ultra-high-strength bolt. ISIJ Int. 2020, 60, 1108-1126. [CrossRef]

Publisher's Note: MDPI stays neutral with regard to jurisdictional claims in published maps and institutional affiliations.

(C) 2020 by the authors. Licensee MDPI, Basel, Switzerland. This article is an open access article distributed under the terms and conditions of the Creative Commons Attribution (CC BY) license (http://creativecommons.org/licenses/by/4.0/). 